\title{
Toxicity of Barringtonia asiatica Seed Extract Against Chilo sachariphagus
}

\author{
Rohendi, Danar Dono*, Andang Purnama \\ Department of Plant Pests and Diseases, Agriculture Faculty, Universitas Padjadjaran, Jatinangor, West Java, Indonesia, \\ 45363 \\ *Corresponding Author: danar.dono@unpad.ac.id.
}

\begin{abstract}
ABTRACT
Barringtonia asiatica is one of the plants that the seeds extracts has insecticidal properties. However, the bioactivity of this seed extract has not been tested against Chilo sacchariphagus larvae which is the main pests in sugar cane. The treatment was carried out at several levels of concentration of methanolic seed extract of B. asiatica. The $15 \mathrm{~cm}$ of fresh sugarcane shoot dipping into the extract solution in some second. After the solution of extract on the sugarcane shoot dried, the first instar of larvae infested to the sugarcane shoot and then put into $20 \mathrm{~cm}$ test tube with $3 \mathrm{~cm}$ of diameter. The duration of feeding on treated sugarcane shoot was two days and on the following day the larvae were fed on sugar cane shoots until the survived larvae reached the $5^{\text {th }}$ instar. The results of the experiment indicated that B. asiatica seed extract was toxic to $C$. sacchariphagus with an $\mathrm{LC}_{50}$ value of $0.398 \%$ at 16 days after treatment. Besides toxic, B. asiatica seed extract also has atifeedant activity, and inhibits the growth of immature of $C$. sacchariphagus in all tested concentrations.
\end{abstract}

Keyword: Toxicity, antifeedant, lethal concentration, Barringtonia asiatica, Chilo sachariphagus

\section{ABSTRAK}

\section{Toksisitas Ekstrak Biji Barringtonia asiatica terhadap Chilo sachariphagus}

Barringtonia asiatica merupakan salah satu tanaman yang ekstrak bijinya berperan sebagai insektisida. Namun bioaktivitas esktrak biji tumbuhan ini belum diuji toksisitasnya terhadap larva Chilo sachariphagus yang merupakan hama utama pada tanaman tebu. Pengujian dilakukan pada beberapa tingkat konsentrasi ekstrak metanol biji $B$. asiatica dengan metode pencelupan pelepah pucuk tebu ke dalam larutan ekstrak. Setelah larutan ekstrak pada pelepah pucuk tebu mongering kemudian diinfestasi dengan larva C.sacchariphagus instar 1 sebayak 10 ekor lalu dimasukkan ke dalam tabung reaksi. Lama pemberian pakan perlakuan selama dua hari dan pada hari selanjutnya larva diberi makan pelepah pucuk tebu hingga larva yang bertahan hidup mencapai instar 5. Hasil penelitian menunjukkan bahwa ekstrak biji $B$. asiatica toksik terhadap C. sacchariphagus dengan nilai $1 C_{50} 0,398 \%$ pada 16 hari setelah perlakuan. Selain bersifat toksik, ekstrak biji B. asiatica juga memiliki aktivitas entifidan dan menghambat pertumbuhan $C$. sacchariphagus pada semua konsentrasi yang diuji.

Kata kunci: Toksisitas, antifidan, konsentrasi letal, Barringtonia asiatica, Chilo sacchariphagus

\section{PENDAHULUAN}

Barringtonia asiatica (L) Kurz.

(Lecythidaceae) merupakan salah satu tumbuhan yang berpotensi untuk dikembangkan sebagai insektisida nabati. Ekstrak methanol biji $B$. asiatica memperlihatkan aktivitas insektisida yang paling kuat dibandingkan dengan ekstrak daun dan kulit batang dengan $\mathrm{LC}_{50}$ sebesar 0,75 terhadap kematian larva $C$. pavonana instar dua sampai instar empat (Dono \& Sujana, 2007). Hasil penelitian Herlt et al. (2002) menyebutkan bawa $B$. asiatica memberikan efek antifeedant terhadap larva Epilachna sp. hasil uji fitokimia menunjukkan bahwa pada ekstrak $B$. asiatica mengandung terpenoid dan saponin (Mojika \& Micor, 2007).

Tanaman tebu (Saccharum offichinarum L.) merupakan salah satu tanaman perkebunan yang memiliki nilai ekonomi yang tinggi. Namun, tanaman tebu memiliki beberapa jenis hama penting, salah satu diantaranya adalah penggerek batang bergaris Chilo sacchariphagus Boj. (Subiyakto, 2016). Kerusakan batang tebu akibat serangan hama penggerek batang pada umur 3 bulan adalah 6,69\% dan dapat terus meningkat (Meidalima \& Kawaty, 2015). Seiring dengan kesadaran akan pentingnya kesehatan tubuh dan lingkungan diperlukan tindakan pengendalian hama yang lebih ramah lingkungan dibandingkan dengan penggunaan insektisida konvensional (insektisida sintetik). Salah satu alternatif tindakan pengendalian yang lebih ramah lingkungan yaitu menggunakan insektisida yang berasal dari ekstrak biji tumbuhan $B$. asiatica.

Berdasarkan penelusuran literatur menunjukkan bahwa masih sedikit informasi yang melaporkan pengaruh ekstrak biji $B$. asiatica terhadap aspek biologi larva $C$. saccharipagus. Oleh karena itu, ekstrak biji $B$. asiatica perlu di uji pengaruhnya terhadap ulat penggerek batang $C$. saccharipagus, khususnya terhadap mortalitas, konsumsi pakan dan pertumbuhan pradewasanya.

\section{BAHAN DAN METODE}

\section{Pemeliharaan dan Penyediaan larva $C$. saccahariphagus.}

Koleksi larva diperoleh dari batang tebu yang terserang $C$. sacchariphagus di pertanaman tebu PT PG Rajawali II Jatitujuh. Larva yang diperoleh 
kemudian dipelihara dalam kotak plastik berukuran 30 $\mathrm{cm}$ x $20 \mathrm{~cm}$ x $8 \mathrm{~cm}$ dan diberi makan pelepah sogolan tebu segar hingga larva berubah menjadi pupa. Pupa kemudian diletakkan pada cawan petri yang telah diberi kapas basah, lalu dimasukkan ke dalam kurungan kasa yang telah diletakkan bibit tanaman tebu sebagai tempat peletakan telur. Telur-telur yang diletakkan oleh imago betina pada daun tebu diambil kemudian dipindahkan ke dalam tabung reaksi yang ditutupi dengan kain kassa. Larva yang menetas dipelihara dalam tabung reaksi yang telah berisi potongan pelepah sogolan tebu segar. yang diganti setiap 3 hari sekali.

\section{Pembuatan ekstrak biji Barringtonia asiatica.}

Biji B. asiatica yang digunakan dalam percobaan ini diperoleh dari tanaman $B$. asiatica yang tumbuh disekitar wilayah kecamatan Jatinangor, Sumedang pada ketinggian $700 \mathrm{~m}$ dpl. Biji dipotongpotong sepanjang 1-2 cm, dikeringudarakan selama kurang lebih 1 minggu. Biji $B$. asiatica dihaluskan dan diekstraksi dengan pelarut methanol dengan perbandingan bobot bahan dan pelarut 1:10 (w/v) selama 3 x 24 jam, selanjutnya disaring menggunakan corong yang dilengkapi kertas saring. Selanjutnya, hasil penyaringan dipekatkan dengan rotary evaporator pada suhu $55-60^{\circ} \mathrm{C}$ dan penghampaan pada tekanan 580-600 $\mathrm{mmHg}$ sehingga diperoleh ekstrak metanol biji B. asiatica.

Berat serbuk biji $B$. asiatica sebesar $1.160 \mathrm{~g}$ (kadar air 14,34\%) menghasilkan ekstrak sebesar 406, $73 \mathrm{~g}$ (rendeman 40,93\%). Ekstrak kasar yang diperoleh disimpan di dalam lemari es pada suhu $4^{\circ} \mathrm{C}$ dan dikeluarkan pada saat dibutuhkan untuk pengujian.

\section{Pelaksanaan percobaan}

Konsentrasi ekstrak biji B. asiatica yang digunakan yaitu $1,0 \% ; 0,8 \% ; 0,5 \% ; 0,3 \% ; 0,1 \%$; $0,05 \%$ dan kontrol yang ditentukan berdasarkan hasil uji pendahuluan. Untuk memperoleh larutan dengan konsentrasi yang diinginkan, ekstrak biji $B$. asiatica dengan berat tertentu dilarutkan dalam larutan yang mengandung perekat - perata alkaril poliglikoleter (Agrostick) $1 \%$. Sebagai perlakuan kontrol digunakan larutan tersebut tanpa ekstrak.

Pelepah sogolan tebu segar dicelupkan ke dalam larutan ekstrak biji $B$. asiatica sesuai konsentrasi perlakuan. Pencelupan dilakukan selama 2 menit sampai seluruh potongan pelepah sogolan tebu tersebut terbasahi oleh larutan larutan ekstrak biji $B$. asiatica yang kemudian dikeringanginkan. Sogolan tebu yang telah diberi perlakuan tersebut kemudian dimasukkan ke dalam tabung reaksi (diameter 2,8 cm dan Panjang $20 \mathrm{~cm}$ ), lalu sebanyak 10 ekor larva instar 1 dimasukkan ke dalam tabung reaksi yang telah berisi potongan sogolan tebu tersebut.
Peubah yang diamati yaitu mortalitas larva uji, konsumsi pakan dan berat serangga uji. Bobot awal sogolan tebu sebelum dimakan larva ditimbang dan dicatat, kemudian setelah 2 hari masa makan larva, bobot sogolan ditimbang kembali. Selisih bobot sogolan awal dengan bobot akhir (setelah dikonsumsi larva) merupakan bobot pakan yang dikonsumsi larva. Konsumsi pakan dinyatakan dala persen (\%). Bobot serangga yang diukur yaitu bobot larva instar III, IV, $\mathrm{V}$ dan bobot pupa.

Percobaan disusun dalam Rancangan Acak lengkap (RAL) dengan tiga kali ulangan Data hubungan konsentrasi denga mortalitas serangga uji dianalisis dengan analisis probit. Data konsumsi pakan dan bobot larva uji yang bertahan hidup disajikan dalam bentuk nilai rata-rata \pm simpangan baku $(X \pm \mathrm{SB})$

\section{HASIL DAN PEMBAHASAN}

\section{Pengaruh Ekstrak Biji B. asiatica terhadap Mortalitas Larva C.sacchariphagus.}

Ekstrak biji B. asiatica pada setiap konsentrasi uji dengan metode pencelupan makanan menyebabkan kematian pada larva $C$. sacchariphagus. Konsentrasi ekstrak yang menyebabkan mortalitas sebesar $87,5 \%$ diperoleh pada taraf konsentrasi ekstrak 1\%, sedangkan konsentrasi yang menyebabkan mortalitas larva $C$. sacchariphagus sebesar $12,5 \%$ diperoleh pada taraf konsentrasi ekstrak $0,05 \%$ pada 16 hari aplikasi (Tabel 1 dan Gambar 1).

Tabel 1. Persentase mortalitas larva C.sacchariphagus dengan metode pencelupan makanan pada 16 hari setelah perlakuan

\begin{tabular}{cc}
\hline Konsentrasi & Mortalitas Larva \\
Ekstrak (\%) & C.sacchariphagus \\
\hline kontrol & 7,5 \\
0,05 & 12,5 \\
0,1 & 25,0 \\
0,3 & 40,0 \\
0,5 & 55,0 \\
0,8 & 70,0 \\
1,0 & 87,5 \\
\hline
\end{tabular}

Angka mortalitas pada serangga uji mengalami peningkatan sesuai dengan taraf konsentrasi yang diujikan. Semakin tinggi konsentrasi yang diaplikasikan dan waktu pengamatan yang semakin panjang, maka angka mortalitas terus mengalami peningkatan. Hal ini menunjukkan bahwa mortalitas larva $C$. sacchariphagus terpaut peningkatan konsentrasi ekstrak $B$. asiatica, dengan kata lain persentase mortalitas larva meningkat sejalan dengan peningkatan konsentrasi ekstrak. Ekstrak 
metanol biji $B$. asiatica memperlihatkan aktivitas insektisida yang paling kuat dibandingkan dengan ekstrak kulit batang dan daun dengan $\mathrm{LC}_{50}$ sebesar 0,75\% (Dono \& Sujana, 2007).

Larva $C$. sacchariphagus yang mati karena perlakuan ekstrak biji $B$. asiatica menunjukkan gejala mula-mula ukuran tubuh terlihat lebih kecil bila dibandingkan dengan ukuran tubuh larva pada kontrol, selanjutnya tubuh larva akan berangsurangsur mengering, berwarna kehitaman dan pada akhirnya mati. Berdasarkan kecenderungan perkembangan kematian larva. Mortalitas larva $C$. sacchariphagus terendah ditujukan pada taraf konsentrasi $0,05 \%$ dan angka tertinggi ditunjukkan pada taraf konsentrasi $1 \%$ bila dibandingkan dengan taraf konsentrasi lainnya dan kontrol. Pengaruh ekstrak $B$. asiatica terhadap mortalitas larva $C$. sacchariphagus diperkuat dengan hubungan hasil analisis probit. Hasil analisis probit terhadap data mortalitas larva $C$. sacchariphagus menunjukkan nilai LC $_{50}$ pada $2 \mathrm{HSP}$ sampai $8 \mathrm{HSP}$ dan cenderung mengalami peningkatan dan cenderung stabil pada 10 HSP sampai 16 HSP (Tabel 2).

Secara umum dapat dikemukakan bahwa ekstrak biji B. asiatica memiliki aktivitas insektisida yang cukup insektisida nabati dengan cara masuk racun perut (stomach poison) yang dapat membunuh serangga jika termakan dan masuk ke dalam organ pencernaan. Retnasari et al. (2017) menyatakan bahwa aktivitas insektisida dari $B$. asisatica salah satunya adalah bersifat racun perut.

\section{Pengaruh Ekstrak Biji B. asiatica terhadap Volume Berat Pakan yang Dikonsumsi.}

Pengaruh ekstrak biji $B$. asiatica terhadap aktivitas makan larva ditunjukkan dengan persentase pakan yang dikonsumsi larva setelah hari ke-2 aplikasi. Volume pakan yang dikonsumsi $C$. sacchariphagus pada perlakuan lebih sedikit dibandingkan dengan volume pakan yang dikonsumsi pada kontrol. Perlakuan ekstrak biji B. asiatica pada konsentrasi $0,05 \%$ mengakibatkan larva $C$. sacchariphagus instar I masih dapat mengkonsumsi daun sebesar $10,94 \%$ pada 2 HSA, sedangkan pada perlakuan $1 \%$ larva instar II C.sacchariphagus hanya memakan daun sebesar 0,997\% (Tabel 3). Hal ini membuktikan ekstrak $B$. asiatica memiliki zat antifeedant atau penghambatan aktivitas makan yang diduga merupakan salah satu faktor penyebab mortalitas. Kandungan ekstrak methanol biji $B$.

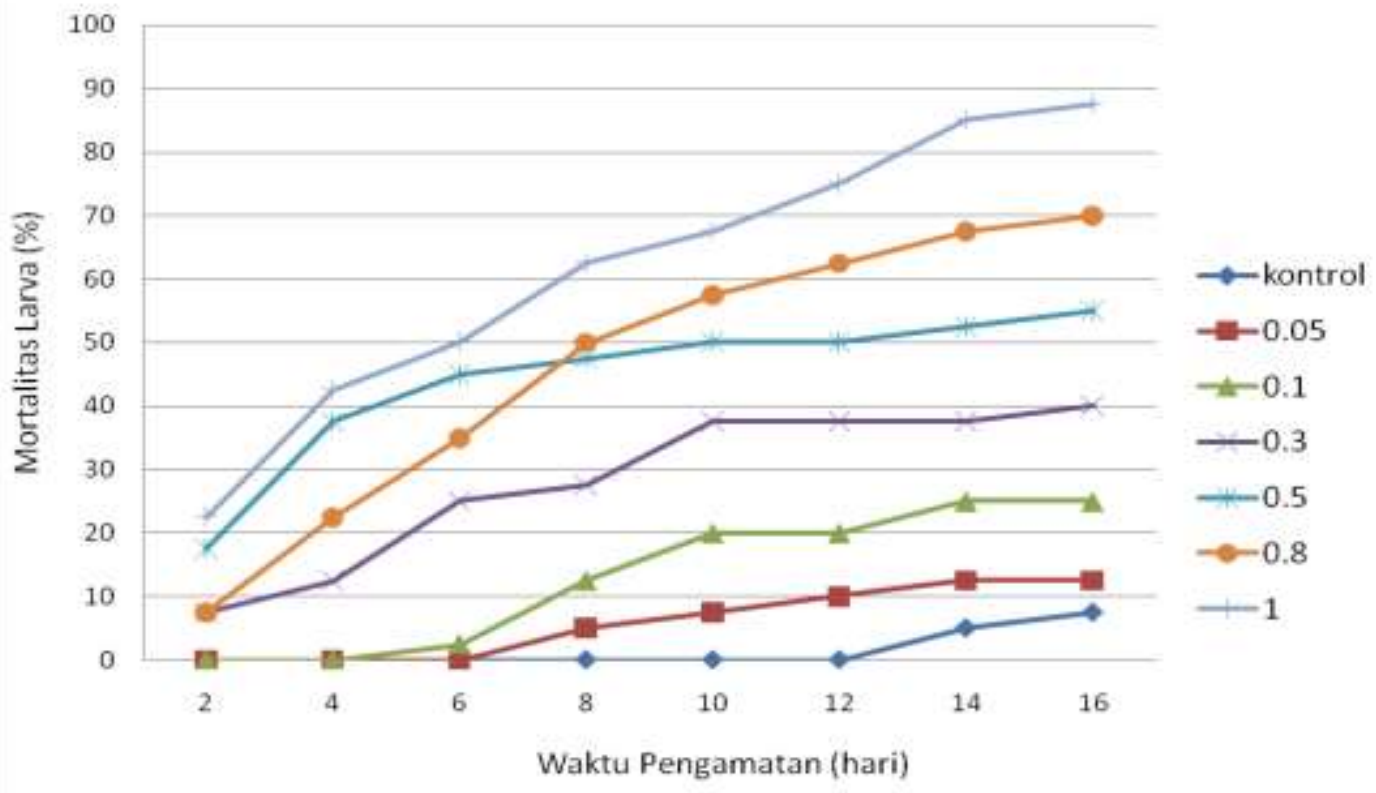

kuat dalam menyebabkan kematian larva $C$. asiatica mengindikasikan sifat antifeedan sacchariphagus. Akan tetapi hal ini tetapi (penghambat makan) (Dono \& Sujana, 2007). menunjukkan bahwa ekstrak B. asiatica merupakan

Gambar 1. Perkembangan mortalitas larva C.sacchariphagus setelah perlakuan ekstrak biji B. asiatica. 
Tabel 2. Hasil analisis probit pengujian ekstrak biji B. asiatica terhadap larva C.sacchariphagus 16 hari setelah aplikasi

\begin{tabular}{|c|c|c|c|c|c|c|c|}
\hline $\begin{array}{l}\text { Waktu Pengamatan } \\
\text { (HAS) }\end{array}$ & $\mathrm{a} \pm \mathrm{SE}$ & $\mathrm{b} \pm \mathrm{SE}$ & Nilai LC $_{50}(\%)$ & $\begin{array}{c}\text { Selang } \\
\text { Kepercayaan } \\
(95 \%) \\
\end{array}$ & $\begin{array}{c}\text { NIlai } \\
\mathrm{LC}_{95}(\%)\end{array}$ & $\begin{array}{c}\text { Selang } \\
\text { Kepercayaan } \\
(95 \%) \\
\end{array}$ & (g) \\
\hline 2 & $1,44 \pm 0,43$ & $-0,82 \pm 0,43$ & 3,714 & - & 51,23 & - & 0,969 \\
\hline 4 & $1,89 \pm 0,38$ & $-0,19 \pm 0,38$ & 1,261 & - & 9,39 & - & 0,706 \\
\hline 6 & $1,90 \pm 0,33$ & $0,44 \pm 0,33$ & 0,948 & $0,61 \pm 2,84$ & 6,92 & $2,49 \pm 356,5$ & 0,362 \\
\hline 8 & $1,45 \pm 0,22$ & $0,26 \pm 0,22$ & 0,666 & $0,49 \pm 0,98$ & 9,07 & $4,20 \pm 37,14$ & 0,093 \\
\hline 10 & $1,56 \pm 0,22$ & $0,43 \pm 0,22$ & 0,529 & $0,41 \pm 0,72$ & 5,98 & $3,15 \pm 18,20$ & 0,079 \\
\hline 12 & $1,40 \pm 0,20$ & $0,50 \pm 0,20$ & 0,437 & $0,33 \pm 0,60$ & 6,48 & $3,23 \pm 21,93$ & 0,082 \\
\hline 14 & $1,65 \pm 0,26$ & $0,65 \pm 0,26$ & 0,403 & $0,26 \pm 0,62$ & 4,03 & $1,86 \pm 26,43$ & 0,195 \\
\hline 16 & $1,85 \pm 0,30$ & $0,74 \pm 0,30$ & 0,398 & $0,37-0,60$ & 3,08 & $1,83 \pm 8,15$ & 0,105 \\
\hline keterangan : & \multicolumn{7}{|c|}{$\mathrm{a}=$ Intersep } \\
\hline & \multicolumn{7}{|c|}{$\begin{array}{l}\mathrm{B}=\text { Kemiringan garis regresi } \\
\mathrm{SE}=\text { Standar Error } \\
\mathrm{LC}=\text { Lethal concentration }(\%) \\
\mathrm{g}=\text { Nilai ketelitian penduga }\end{array}$} \\
\hline
\end{tabular}

Arivoli \& Tennyson (2013) menyebutkan bahwa pada aktivitas antifeedant yang lebih tinggi ditunjukkan dengan penurunan aktivtas makan. Zat tersebut juga memodifikasi perilaku yang menghalangi makan melalui aksi langusng terhadap sensila peripheral (organ pengecap) (Isman et al., 1996). Jadi, mortalitas larva dalam pengujian ini merupakan akibat dari senyawa toksik dan senyawa penghambatan aktivitas makan larva yang berasal dari ekstrak biji $B$. asiatica.

Kemampuan ekstrak untuk menyebabkan penghambatan aktivitas makan pada larva C.sacchariphagus sangat dipengaruhi oleh serangga itu sendiri, karena senyawa antifeedant yang terdapat pada ekstrak merupakan senyawa kimia yang hanya dapat mencegah serangga untuk makan tapi tidak dapat menyebabkan kematian secara langsung.

Pengaruh Ekstrak Biji $B$. asiatica terhadap berat Larva Instar ke-2, ke-4 dan ke-5 C.sacchariphagus. Perlakuan ekstrak biji $B$. asiatica pada konsentrasi $0,05 \%$ mengakibatkan larva $C$. sacchariphagus instar ke-3 mengalami pertumbuhan rata-rata berat sebesar 0,046 gram dan terjadi penurunan pada rataan instar berikutnya yaitu 0,66 gram pada instar ke-4 dan 0,177 gram instar ke-5. Akan tetapi penurunan rataan tersebut tidak terlalu signifikan bila dibandingkan dengan uji konsentrasi lainnya, seperti pada uji konsentrasi $1 \%$ instar ke-3 yang mengalami pertumbuhan rataan 0,039 gram dan terus menurun pada instar ke-4 sebesar 0,048 gram dan 0,025 gram pada instar ke-5. Pada fase pupa, juga terjadi penurunan rataan berat antar setiap konsentrasi ekstrak.. Hal ini dapat dilihat dari konsentrasi $0.05 \%$ memiliki berat rataan pupa sebesar 0,12 gram dan terjadi penurunan pada konsentrasi $0,1 \%$ sebesar 0,085 gram dan konsentrasi 0,3\% sebesar 0,04 gram bahkan pada konsentrasi konsentrasi yang lebih tinggi larva tidak dapat menjadi pupa. Hal ini menunjukkan ekstrak B. asiatica juga menyebabkan penghambatan pertumbuhan larva $C$. sacchariphagus yang diduga akibat rendahnya aktivitas makan larva akibat pengaruh dari bahan aktif ekstrak biji $B$. asiatica tersebut. Aktivitas makan yang rendah pada larva mengakibatkan energi untuk perkembangan larva menjadi berkurang. Selain itu, ada kemungkinan disebabkan oleh terganggunya fungsi organ yang menghasilkan hormon pertumbuhan. Gangguan pada permeabilitas sel yang diakibatkan oleh saponin juga memungkinkan zat racun masuk dan mengganggu proses metabolisme larva sehingga larva akan kekurangan energi (Ningsih dkk., 2012).

Tabel 3. Persentase berat sogolan tebu yang di konsumsi larva C.sacchariphagus pada uji toksisitas dengan metode pencelupan makanan pada 2 hari setelah perlakuan (HSP)

\begin{tabular}{cc}
\hline $\begin{array}{c}\text { Konsentrasi } \\
\text { Ekstrak }\end{array}$ & $\begin{array}{c}\text { Pakan yang di konsumsi } \\
\text { larva } \\
(\%)(\mathrm{x} \pm \mathrm{SB})\end{array}$ \\
\hline kontrol & $12,5 \pm 1,12$ \\
0,05 & $10,94 \pm 0,86$ \\
0,10 & $9,24 \pm 0,93$ \\
0,30 & $7,63 \pm 0,51$ \\
0,50 & $5,51 \pm 0,52$ \\
0,80 & $4,94 \pm 1,04$ \\
1,00 & $0,997 \pm 0,29$ \\
\hline
\end{tabular}

Keterangan : $\mathrm{x} \quad=$ rata-rata luas yang dikonsumsi larva $(\%)$

$\mathrm{SB}=$ Simpangan baku 
Tabel 4. Berat larva instar ke-3, ke-4, ke-5 dan pupa $C$. sacchariphagus dengan metode uji pencelupan makanan

\begin{tabular}{|c|c|c|c|c|c|c|c|c|}
\hline $\begin{array}{l}\text { Konsentrasi } \\
\text { Ekstrak }(\%)\end{array}$ & $\begin{array}{c}\text { Berat larva } \\
\text { instar } 3 \text { (gram) } \\
\quad(\mathrm{x} \pm \mathrm{SB})\end{array}$ & $\mathrm{N}$ & $\begin{array}{c}\text { Berat larva } \\
\text { instar } 4 \text { (gram) } \\
\quad(x \pm \text { SB })\end{array}$ & $\mathrm{N}$ & $\begin{array}{l}\text { Berat larva instar } 5 \\
(\text { gram })(x \pm S B)\end{array}$ & $\mathrm{N}$ & $\begin{array}{l}\text { Berat Pupa } \\
\quad \text { (gram) }\end{array}$ & $\mathrm{N}$ \\
\hline Kontrol (0) & $0,280 \pm 0,4400$ & 39 & $0,670 \pm 0,0013$ & 33 & $0,180 \pm 0,0605$ & 28 & $0,120 \pm 0,0105$ & 12 \\
\hline 0,05 & $0,046 \pm 0,0005$ & 35 & $0,066 \pm 0,0024$ & 31 & $0,177 \pm 0,0700$ & 25 & $0,120 \pm 0,0063$ & 9 \\
\hline 0,10 & $0,045 \pm 0,0008$ & 30 & $0,064 \pm 0,0402$ & 25 & $0,143 \pm 0,2760$ & 19 & $0,085 \pm 0,0078$ & 6 \\
\hline 0,30 & $0,045 \pm 0,0013$ & 25 & $0,077 \pm 0,0017$ & 21 & $0,251 \pm 0,0034$ & 18 & $0,040 \pm 0,0400$ & 4 \\
\hline 0,50 & $0,044 \pm 0,0010$ & 19 & $0,056 \pm 0,0015$ & 15 & $0,070 \pm 0,0029$ & 11 & 0 & 0 \\
\hline 0,80 & $0,043 \pm 0,0005$ & 14 & $0,550 \pm 0,0029$ & 11 & $0,064 \pm 0,0057$ & 6 & 0 & 0 \\
\hline 1,00 & $0,039 \pm 0,0005$ & 6 & $0,048 \pm 0,0225$ & 3 & $0,025 \pm 0,0290$ & 1 & 0 & 0 \\
\hline
\end{tabular}

Keterangan :

$\mathrm{x}=$ rata-rata berat pakan yang dikonsumsi larva $(\%)$

$\mathrm{SB}=$ Simpangan baku

$\mathrm{N}$ = Jumlah serangga yang masih hidup

\section{KESIMPULAN}

Ekstrak biji Barringtonia asiatica bersifat toksik terhadap C.sacchariphagus dengan nilai $\mathrm{LC}_{50}$ sebesar $0,398 \%$ pada 16 hari setelah perlakuan. Selain toksik, ekstrak biji $B$. asiatica juga memiliki aktivitas penghambat makan, dan menghambat pertumbuhan pradewasa $C$. sacchariphagus pada semua konsentrasi yang diujikan.

\section{UCAPAN TERIMA KASIH}

Terima kasih disampaikan kepada Pimpinan dan seluruh staf R \& D PT PG Rajawali II Jati Tujuh yang telah memfasilitasi penelitian ini hingga dapat terlaksana dengan baik.

\section{DAFTAR PUSTAKA}

Arivoli, S \& S. Tennyson. 2013. Antifeedant activity, developmental indices and morphogenetic variations of plant extracts against Spodoptera litura (Fab) (Lepidoptera: Noctuidae). Journal of Entomology and Zoology Studies. 1 (4): 87-96

Dono, D. \& N. Sujana. 2007. Aktivitas insektisida ekstrak daun kulit batang, dan biji Barringtonia Asiatica (lecythidaceae) terhadap larva Crocidolomia pavonana (Lepidoptera: Pyralidae). Disampaikan pada Simposium Nasional PEI, revitalisasi Penerapan PHT Dalam Praktek Pertanian Yang baik menuju Sistem Pertanian Berkelanjutan, Sukamandi 10-11 april 2007

Herlt, AJ. LN, Mander, E. Pongoh, RJ. Rumampuk, \& P.Tarigan. 2002. Two Major Saponins from Seeds of Barringtonia asiatica: Putative
Antifeedants toward Epilachna sp. Larvae.J. Nat. Prod.,65 (2), 115-120. DOI: $10.1021 / \mathrm{np} 000600 \mathrm{~b}$

Isman, M.B., H. Matsumura, S. MacKinnon, T. Durst, G.H.N. Towers \& J.T. Arnason, 1996. Phytochemistry of the Meliaceae: So many terpenoids, so few insecticides. Recent Advances in Phytochemistry, 30, 155-178.

Meidalima, D. \& R.R. Kawaty. 2015. Eksplorasi dan Pengamatan Intensitas Serangan Hama Penting Tanaman Tebu di PTPN VII, Cinta Manis Sumatera Selatan. Biosaintifika 7 (1): 68-76.

Mojica, E.E. \& J.R.L. Micor. 2007. Bioactivity study of Barringingtonia asitica (Linnaeus) Kurz. Seed Aqueous Extract in Artemia salina. Internasional journal of botany. 3(3): 325328.

Ningsih, T. U., Yuliani \& T. Haryono. 2012. Pengaruh filtrat umbi gadung, daun sirsak dan herba anting-anting terhadap mortalitas larva Spodoptera litura. Lentera Bio 2(1): 33-36.

Retnasari, E., LT., Puspasari, R. Meliansayah, R. Maharani, Y. Hidayat, \& D. Dono. 2017. Toxicity of Barringtonia asiatica L. (KURZ.), Melia azedarach L. and Annona muricata L. Seed Extract Mixture Against Larvae Crocidolomia pavonana F. (Lepidoptera: Pyralidae)" in 2nd International Conference on Sustainable Agriculture and Food Security: A Comprehensive Approach, KnE 
Life Sciences, pages 246-255. DOI 10.18502/kls.v2i6.1046

Subiyakto. 2016. Hama penggerek tebu dan perkembangan teknik pengendaliannya.
Jurnal Litbang Pertanian. 35(4):179-186.

DOI: $\quad 10.21082 / j p 3 . v 35 n 4.2016 . p 179-186$. 